\title{
Initial self-blame predicts eating disorder remission after 9 years
}

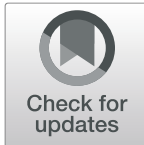

Suzanne Petersson ${ }^{1,2^{*}}$ D, Andreas Birgegård ${ }^{3}$, Lars Brudin ${ }^{4,5}$, Emma Forsén Mantilla ${ }^{3,6,7}$, Elin Monell ${ }^{3}$, David Clinton ${ }^{3,8}$ and Caroline Björck ${ }^{9}$

\begin{abstract}
Background: Research into predictors of outcome in eating disorders (ED) has shown conflicting results, with few studies of long-term predictors and the possible importance of psychological variables that may act as risk- and maintenance factors.

Aim: To identify baseline predictors of ED remission nine years after initial clinical assessment using self-report measures of ED psychopathology, psychiatric symptoms, and self-image in a sample of adult ED patients $(N=104)$ treated at specialist units in Stockholm, Sweden. Sixty patients participated in the follow-up, of whom 41 patients (68\%) had achieved remission.

Results: Results suggested that the only significant predictor of diagnostic remission after nine years was initial levels of self-blame.

Conclusion: In order to ensure long-term recovery in ED it may be important for clinicians to widen their therapeutic repertoire and utilise techniques that reduce self-blame and increase self-compassion.

Plain English summary: It is difficult to predict how an eating disorder will develop, and research has found varying factors that affect the outcome of the condition. Recovery rates vary from nearly nil to over $90 \%$. This variation could be explained by different research factors, but are more likely due to varying definitions of 'recovery', with less stringent definitions yielding high recovery rates and more stringent definitions yielding lower rates. The present study investigated whether the severity of eating disorder symptoms and other psychiatric symptoms could predict recovery nine years from first admission to specialised eating disorder care. Sixty patients at three eating disorder treatment units participated, and their scores on self-report measures of symptoms were used as predictor variables. Forty-one participants had no eating disorder diagnosis at nine-year follow-up. Most participants with binge-eating disorder had recovered, while the poorest outcome was found for anorexia nervosa with slightly over half of patients recovered after nine years. The only predictor for the nine-year outcome was a higher initial rating of self-blame, measured with the Structural Analysis of the Social Behavior. It was concluded that it may be important for clinicians to detect and address self-blame early in the treatment of eating disorders in order to enhance the possibility of recovery. Treatment should focus on reducing self-blame and increasing selfacceptance.
\end{abstract}

Keywords: Eating disorders, Outcome, Prediction, Self-image

\footnotetext{
* Correspondence: suzanne.petersson@regionkalmar.se

'Department of Rehabilitation, Kalmar Regional Council, Hus 13, plan 7, 391

85, Länssjukhuset, Kalmar, Sweden

${ }^{2}$ Department for Medicine and Optometry, Linnaeus University, Kalmar,

Sweden

Full list of author information is available at the end of the article
}

(c) The Author(s). 2021 Open Access This article is licensed under a Creative Commons Attribution 4.0 International License, which permits use, sharing, adaptation, distribution and reproduction in any medium or format, as long as you give appropriate credit to the original author(s) and the source, provide a link to the Creative Commons licence, and indicate if changes were made. The images or other third party material in this article are included in the article's Creative Commons licence, unless indicated otherwise in a credit line to the material. If material is not included in the article's Creative Commons licence and your intended use is not permitted by statutory regulation or exceeds the permitted use, you will need to obtain permission directly from the copyright holder. To view a copy of this licence, visit http://creativecommons.org/licenses/by/4.0/. The Creative Commons Public Domain Dedication waiver (http://creativecommons.org/publicdomain/zero/1.0/) applies to the data made available in this article, unless otherwise stated in a credit line to the data. 


\section{Introduction}

Research into predictors of outcome in eating disorders (ED) has shown conflicting results [1]. This may be due to length of follow-up, definitions of outcome, characteristics of the samples studied, and the assessment methods used. In a meta-analysis of 126 studies Vall and Wade [1] found that the most robust predictor outcome at end of treatment and follow-up was symptom change during early treatment. Other important variables included illness duration, weight and shape concern, general psychopathology, ED pathology, and self-esteem. However, among the 126 studies examined by Vall and Wade [1], follow-ups after more than two years were rare, few instruments assessed psychological variables that may act as both risk- and maintenance factors, while definitions of outcome and remission varied considerably.

Some studies that have investigated initial predictors of long-term outcome have found that poor long-term outcome is associated with poor social relationships prior to onset of illness, as well as extreme and compulsive drive to exercise [2]; high weight- and shape concern [3]; high scores on the Eating Disorder Inventory [4]; drive for thinness [5]; maturity fears [6]; obsessivecompulsive symptoms [7]; and depression [8]. Initial negative self-image (particularly self-hate) seems to be associated with a less favorable outcome after three years $[9,10]$. Moreover, lower scores on self-blame and higher scores on self-love seem to predict positive 12-month outcome [11]. In these studies, self-image was measured using the Structural Analysis of Social Behavior (SASB) $[12,13]$ model, which has demonstrated associations with a range of ED longitudinal features and outcomes, including suicidality and dropout from treatment [14, 15]; yet thus far the importance of self-image for longterm outcome remains unexplored. SASB stems from interpersonal theory, where self-image is a personality trait-level construct, and is expected to be relatively stable over time [12]. Given the central role that selfimage seems to have as a maintenance factor in EDs, its potential value as a predictor of long-term outcome deserves attention.

Recovery rates for ED vary from nearly nil to $92 \%$ [6, 16]. Such dramatic variation between studies may be due to factors such as the variables investigated, followup times, sample makeup, and attrition. Discrepancies in recovery rates may also, importantly, be due to varying definitions of the outcome variable "recovery" [17-20].

One definition of recovery is that criteria for diagnostic remission have been met for a longer period than required according to diagnostic manuals. However, there is little agreement on the duration of the asymptomatic period required, which has varied between one month and five years in different studies, although three, six, or twelve months is most common [19]. Established diagnostic manuals are of little help. DSM-IV [21] had no recommended time span for defining remission, and although DSM-5 takes steps in the right direction it remains vague, defining full remission as "none of the criteria have been met for a sustained period of time" [21]. In a review of ED recovery Bardone-Cone and colleagues [19] suggested that the definition should include absence of diagnostic criteria for any ED plus scores on psychological ED measures that are indistinguishable from healthy controls but significantly different from people with EDs [19].

In the present study we aimed to explore the potential of self-image, as well as the previously researched outcome predictors of psychiatric comorbidity and severity of ED psychopathology, as baseline predictors of ED remission nine years after first admission to specialist ED care. Since previous results regarding the long-term impact of baseline psychopathology and comorbidity are contradictory, and studies focusing self-image and longterm outcome in EDs are lacking, we did not stipulate any hypotheses in relation to these predictors.

\section{Method \\ Participants}

A consecutive series of adult ED patients (over 18 years of age) entering treatment at either of three publicly funded specialist units in Stockholm, Sweden, between August 2001 and July 2002 was recruited. Initially, a total of 118 patients agreed to participate; 12 declined participation before baseline and initial data for two participants were missing, which meant that 104 participants entered the study. Sixty of these (58\%), all women, completed the same assessments nine years later with complete data and constitute the participants in the present study. Reasons for missing data at follow-up included dropping out from treatment and nonparticipation in assessment, as well as failure to obtain data on all measures. There were no significant differences between drop outs and remaining participants regarding baseline diagnoses $\left(x^{2}=4.86, \alpha=.05\right)$, age (drop outs $M=23.4, S D=6.1$ ), BMI (drop outs $M=21.0, S D=$ 6.4, range 12.9-38.8), or baseline predictor variable scores (see Table 1 for participants' age and BMI). Participating treatment units offered a wide variety of interventions, such as individual, family or group therapies, nutritional treatment, psychopharmacological medication, and expressive forms of treatment, such as art therapy. Although treatment was individually tailored, general foci were restoration of normal eating patterns, problems with self-image, interpersonal relationships, and affect-related difficulties. Data from the present database have been used previously to examine dietary habits [22]. 
Table 1 Means and standard deviations (SD) for baseline variables per outcome group: recovered (= No eating disorder) versus still suffering from eating disorder after 9 years, logistic regression for baseline differences as well as Cohen's $d$ effect sizes for pre-post mean differences. Significant $p$-value in bold

\begin{tabular}{|c|c|c|c|c|}
\hline \multirow[b]{2}{*}{ Variable } & \multirow[b]{2}{*}{ Mean $(S D)$} & \multicolumn{2}{|l|}{ Univariate } & \multirow[b]{2}{*}{ Effect sizes $^{2}$} \\
\hline & & OR $(95 \% \mathrm{Cl})$ & $p$ & \\
\hline \multicolumn{5}{|l|}{ Age (years) } \\
\hline Eating Disorder & $26.1(7.5)$ & 1.00 & & \\
\hline No Eating Disorder & $24.8(5.4)$ & $0.97(0.88-1.06)$ & 0.449 & \\
\hline \multicolumn{5}{|c|}{ Body Mass Index $\left(\mathrm{kg} / \mathrm{m}^{2}\right)$} \\
\hline Eating Disorder & $20.9(5.3)$ & 1.00 & & \\
\hline No Eating Disorder & $23.3(8.0)$ & $1.06(0.96-1.16)$ & 0.252 & \\
\hline \multicolumn{5}{|l|}{ EDI-DT } \\
\hline Eating Disorder & $14.9(5.0)$ & 1.00 & & 0.59 \\
\hline No Eating Disorder & $15.0(4.5)$ & $1.0(0.9-1.1)$ & 0.950 & 1.61 \\
\hline \multicolumn{5}{|l|}{ EDI-BULIMIA } \\
\hline Eating Disorder & $5.3(4.7)$ & 1.00 & & 0.31 \\
\hline No Eating Disorder & $7.2(6.1)$ & $1.06(0.95-1.19)$ & 0.254 & 1.38 \\
\hline \multicolumn{5}{|l|}{ EDI-BD } \\
\hline Eating Disorder & $18.5(7.3)$ & 1.00 & & 0.31 \\
\hline No Eating Disorder & $18.9(7.5)$ & $1.01(0.93-1.09)$ & 0.839 & 1.1 \\
\hline \multicolumn{5}{|l|}{ SCL 90 index } \\
\hline Eating Disorder & $1.69(0.75)$ & 1.00 & & 0.49 \\
\hline No Eating Disorder & $1.68(0.62)$ & $0.98(0.40-2.42)$ & 0.972 & 1.52 \\
\hline \multicolumn{5}{|l|}{ SASB C2 } \\
\hline Eating Disorder & $18.9(15.5)$ & 1.00 & & 1.24 \\
\hline No Eating Disorder & $23.2(17.4)$ & $1.02(0.98-1.05)$ & 0.364 & 1.44 \\
\hline \multicolumn{5}{|l|}{ SASB C3 } \\
\hline Eating Disorder & $25.4(15.2)$ & 1.00 & & 0.83 \\
\hline No Eating Disorder & $30.1(19.0)$ & $1.02(0.98-1.05)$ & 0.351 & 1.3 \\
\hline \multicolumn{5}{|l|}{ SASB C4 } \\
\hline Eating Disorder & $38.1(22.1)$ & 1.00 & & 0.44 \\
\hline No Eating Disorder & $44.6(17.2)$ & $5.2(0.4-75.2)$ & 0.223 & 0.71 \\
\hline \multicolumn{5}{|l|}{ SASB C6 } \\
\hline Eating Disorder & $73.4(20.9)$ & 1.00 & & 0.96 \\
\hline No Eating Disorder & $59.6(23.5)$ & $0.97(0.95-1.00)$ & 0.044 & 1.35 \\
\hline \multicolumn{5}{|l|}{ SASB C7 } \\
\hline Eating Disorder & $62.8(21.7)$ & 1.00 & & 0.92 \\
\hline No Eating Disorder & $51.5(23.1)$ & $0.98(0.95-1.00)$ & 0.088 & 1.3 \\
\hline
\end{tabular}

Abbreviations: EDI Eating Disorder Inventory-2, DT Drive for Thinness, BD Body Dissatisfaction, SCL Symptom Check List-90, SASB Structural Analysis of Social Behaviour. C2 Self-affirmation, C3 Self-love, C4 Self-protection, C6 Self-blame, and C7 Self-hate

${ }^{2}$ Pre-post effect sizes calculated with Cohen's $d$

\section{Measures}

A battery of interviews and self-report measures was used to assess ED, general psychopathology, and relevant psychological variables. The present study utilised a subset of self-report measures.

The Rating of Anorexia and Bulimia (RAB) [23], a semi-structured interview, was used for assessment of
DSM-IV ED [21) diagnoses at admission and followup. The RAB-R has been validated in a clinical sample of Swedish eating disorder patients $(n=71)$ together with a sample of healthy female controls $(n=31)$ and the test has shown satisfactory psychometric properties regarding internal consistency, interrater and test-retest reliability It correlated well with 
related measures, and discriminated between patients and normal controls.

The Eating Disorders Inventory-2 (EDI-2) [4], a selfreport questionnaire with 91 items rated on a 6-point scale with eleven subscales measuring ED symptoms and related psychological variables. Symptom subscales measuring Drive for thinness (Cronbach's alpha in this study was .81), Bulimia $(\alpha=.87)$, and Body Dissatisfaction $(\alpha=.91)$ were used in the study. The Swedish version of the EDI-2 has been validated in three female samples: patients with $\mathrm{ED}(n=978)$; psychiatric outpatients $(n=106)$; and healthy controls $(n=602)$. Ages ranged from 18 to 50 years. Subscales showed high internal consistency and good test-retest reliability and the instrument and its subscales discriminated well between ED patients and healthy controls as well as between different ED diagnoses [24].

The Structural Analysis of Social Behavior (SASB, 3rd surface, self-image) [12, 13] utilises 36 self-referential statements that are rated $0-100$ with 10 -point increments to assess eight aspects (clusters) of self-image: $\mathrm{C} 1$ ) Self-emancipation; C2) Self-affirmation; C3) Active selflove; C4) Self-protection; C5) Self-control; C6) Selfblame; C7) Self-hate; and C8) Self-neglect. The Swedish version of the SASB was validated in a sample with healthy controls ( $n=52,54 \%$ women) and patients with different psychiatric diagnoses ( $n=173,42 \%$ women). The instrument has shown satisfactory psychometric properties regarding internal consistency, and test-retest reliability [25]. Internal consistency and correspondence between U.S. and Swedish versions are good [13, 25, 26]. The SASB has shown to discriminate well between clinical and normal samples [13, 25-28]. Measures of Cronbach's alpha in the present sample were good for: Self-affirmation $\alpha=.76$; Active Self-love $\alpha=.77$; Selfprotection $\alpha=.82$; Self-blame $\alpha=.82$; and Self-hate $\alpha=$ .81 ; but not for Self-neglect $\alpha=.51$; Self-emancipation $\alpha=.45$; or Self-control $\alpha=.41$. Since lower internal consistency (i.e. $<.70)$ for the latter three clusters has also been found in previous studies of Swedish ED patients [29], these clusters were removed from analyses.

The Symptom Check List-90 (SCL-90) [30, 31] was used to measure self-reported psychiatric symptoms. It consists of 90 items rated on a 5-point scale, with 10 subscales: Somatization; Obsession-compulsion; Interpersonal Sensitivity; Depression; Anxiety; Hostility; Phobic Anxiety; Paranoid Ideation; Psychoticism; and Additional Scales. The Swedish version has been validated in healthy controls $(n=1016,73 \%$ women, age range $=18-63$ years) and samples with different psychiatric diagnoses $(n=1782$, 56\% women, age range $=19$ 73 years). For this study the total sum index of all subscales was used to measure general psychiatric health $(\alpha=.97)$.

\section{Procedure}

Administration of intake measures took place prior to treatment or within two to four weeks after commencing treatment. Two trained and experienced ED specialists (one specialist nurse and one psychologist and psychotherapist) conducted baseline and follow-up interviews. At 9-year follow-up, participants were contacted by letter or phone if they were no longer in treatment (true for all but five participants), and an appointment for a follow-up interview at the unit was made. Definition of remission from ED was operationalized as not fulfilling diagnostic criteria for any DSM-IV ED. Self-report measures were mailed to participants and they were asked to return them prior to the interview. If participants were unable to attend personally, telephone interviews were conducted.

\section{Data analysis}

Statistical analyses were performed using STATISTICA 12.0. Logistic regression was used to examine differences between baseline variables and ED remission status after nine years, followed by multiple logistic regression when $p<0.1$. Association between 9-year remission status and baseline ED diagnosis was examined using $x^{2}$.

\section{Results}

Table 1 presents measures of central tendency and dispersion for baseline variables in relation to remission or non-remission after nine years, as well as significance of between-group comparisons using logistic regression. ${ }^{1}$ There were no significant between-group differences on any baseline variables except for SASB Self-blame $(p=$ .044); patients who were later in remission showed significantly lower levels of self-blame at initial presentation compared to patients who later were not in remission and for SASB Self-hate $(p=0.088)$; patients who were later in remission showed significantly lower levels of self-hate at initial presentation compared to patients who were later not in remission.

For those variables with $p<.10$, multiple logistic regression was used to examine the relationship between initial self-assessment measures and ED remission at nine-year follow-up. SASB Self-blame was the only significant predictor of remission: odds ratio $=.97$ (CI .951.0), $p=.041$. Higher baseline levels of self-blame were associated with lower likelihood of remission nine years later. When comparing initial ED diagnoses at baseline for differences in remission status after nine years using $x^{2}$, no significant results were found.

\footnotetext{
1"In order to test for effects of specific SCL-90 subscales, we also tested Depression and Obsession-compulsion as separate variables since these were deemed most relevant to Self-blame and long-term outcome in AN, respectively. However, no baseline differences between outcome groups were found; $p$ s .973 and .964."
} 
An analysis was performed on recovery and possible diagnostic crossover from baseline to nine-year followup for those who still had an ED diagnosis at follow-up (Table 2). Of the 60 patients who participated at followup $41(68 \%)$ were recovered. Recovery was not significantly different as a function of baseline diagnosis. When diagnostic crossover was examined for those patients who were not in remission, the most frequent crossovers were from Anorexia Nervosa (AN) to Other Specified Feeding and Eating Disorders (OSFED), from Bulimia Nervosa (BN) to OSFED, and from OSFED to BN. Forty-four percent of patients with initial AN still had an ED diagnosis at follow-up; about half of these patients had an OSFED diagnosis.

\section{Discussion}

The present study explored whether initial levels of ED psychopathology, psychiatric symptoms, and self-image could predict ED diagnostic remission after nine years, and found that the only significant predictor of remission was initial levels of self-blame. In particular, lower self-blame at initial assessment was associated with higher likelihood of remission nine years later.

AN had the lowest remission rate (56\%), while Binge Eating Disorder (BED) had the highest $(80 \%)$, which is also in line with previous findings [32]. As regards the EDI-2 and SCL-90, which are frequently used in ED research, previous findings have varied regarding the ability of these instruments to predict outcome. Ametller and colleagues [33] found that high scores on the $\mathrm{Bu}$ limia subscale of the EDI-2 predicted whether young patients with AN were still in inpatient treatment after six months, while Quadflieg and Fichter [5] found that EDI2 Drive for Thinness could predict outcome more than eleven years after admission in $\mathrm{BN}$.

High scores on the SCL-90 has been shown to predict ED diagnosis at follow-up in some studies [34, 35], but not others [36]. In the present study the lack of association between the EDI-2 and the SCL-90 on the one hand, and outcome on the other hand, may be due to sample differences or the salience of scantly researched

Table 2 Distribution of baseline diagnoses for those with and without an ED diagnosis at nine-year follow-up, $N$ and percent in relation to status at follow-up

\begin{tabular}{llll}
\hline Baseline Diagnosis & $\begin{array}{l}\text { Baseline } \\
\boldsymbol{N}\end{array}$ & $\begin{array}{l}\text { No ED at follow-up } \\
\boldsymbol{N}(\%)\end{array}$ & $\begin{array}{l}\text { ED at follow-up } \\
\boldsymbol{N}(\%)\end{array}$ \\
\hline AN & 16 & $9(56.2 \%)$ & $7(43.8 \%)$ \\
BN & 17 & $13(76.5 \%)$ & $4(23.5 \%)$ \\
BED & 10 & $8(80 \%)$ & $2(20 \%)$ \\
OSFED & 17 & $11(64.7 \%)$ & $6(35.3 \%)$ \\
Total & 60 & $41(68.3 \%)$ & $19(31.7 \%)$ \\
\hline
\end{tabular}

Abbreviations: AN Anorexia Nervosa, BN Bulimia Nervosa, BED Binge Eating Disorder, OSFED Other Specified Feeding and Eating Disorders psychological variables (such as self-blame) on longterm outcome. Another possibility for the lack of significant findings in relation to the EDI- 2 and the SCL-90 in the present study may be because these instruments measure state-dependent aspects of ED, which fluctuate over time. They may therefore be more relevant for predicting short- and medium-term outcome, whereas the SASB may be more germane for measuring important trait-level personality-based changes over the long-term [12]. Length of follow-up in comparable previous studies was considerably shorter than the present study, with the exception of Quadflieg and Fichter [5] who did not use the SASB.

The relationship between ED and negative selfevaluation as measured by the SASB is well documented [37]. SASB Self-blame, in particular, contains items about accusing and punishing oneself, such as "I accuse and blame myself until I feel guilty, bad and ashamed" and "I make myself do and be things which are known not to be right for me. I fool myself". Such items may be particularly relevant to ED.

It has been argued that ED symptoms may function to regulate negative emotions and aversive thoughts [38]. ED symptoms may act to improve self-perceived flaws in appearance or achievement [39-41]. Self-blame may play a central role in such a functional system by reinforcing negative attitudes toward self and body, and thereby stimulating increased ED behaviours (cf. [42]). Forsén Mantilla and co-workers [28] found that high scores on SASB Self-blame and low scores on SASB Selfaffirmation were associated with ED symptoms.

Viewed in a clinical context, focusing on self-criticism may be essential for achieving long-term recovery from ED. Indeed, initial negative self-image (i.e. high levels of SASB Self-blame and Self-hate) can be reduced to normal levels after ED treatment [43]. The road to longterm recovery in ED may, therefore, not just require symptom-focused interventions, but also therapeutic techniques that increase self-compassion, the opposite of self-blame. It may be important for therapists to confront self-critical thinking and help patients to understand, tolerate, and accept perceived flaws and weaknesses. One way of working actively with self-blame is Compassion-focused Therapy (CFT) where patients are encouraged to develop non-judgemental, compassionate self-correction in relation to one's mistakes and shortcomings, as well as reduce self-criticism and selfblame $[44,45]$. Thus, it may be essential to integrate components of CFT with standard symptom-focused interventions to achieve optimal outcome [46]. Future research could address the question of whether optimal long-term outcome in ED patients generally or in specific subgroups is mediated by interventions that reduce self-blame. 


\section{Limitations}

Strengths of the study were its longitudinal design with a nine-year follow-up and the use of well validated instruments that assessed important psychological variables relevant to ED as well as indices of ED and general psychopathology. Another strength was the naturalistic sample, comprising patients with a variety of ED diagnoses, ages, and a wide range of psychiatric symptoms as measured by the SCL-90, which increases representativeness and generalisability in relation to adult ED patients as they present in the community.

Nevertheless, there were also a number of limitations. The sample size was relatively small for this type of investigation, which reduces power and thus the generalizability. Self-report data was used, entailing risks of response bias. However, using well established, valid, and reliable measures ensured that the study variables were assessed in the same way. Data on number of previous treatment episodes, treatment duration, and current treatment could not be collected, which meant it was not possible to use such variables as covariates. The relevance of the outcome measure (diagnostic remission) can be criticised for being crude. As Bardone-Cone and colleagues [19] have pointed out, diagnostic remission can be considered to be a necessary but insufficient definition of recovery. Future research may therefore do well to utilise a more multifaceted measure of outcome.

\section{Conclusion}

These results confirm previous findings of the predictive capacity of the SASB self-image, and underscore the centrality of self-blame, self-criticism, or in SASB parlance negative self-control, for ED symptomatology. These findings may suggest that when such tendencies are detected in the clinic, therapeutic interventions should focus on reducing self-blame and fostering selfacceptance.

\section{Clinical implications}

Despite a plethora of research, ED remain difficult to treat and treatment results are often disheartening for patients, families and therapists. By attuning to tendencies toward self-blame early in treatment and fostering the development of a healthier self-image it may be possible to help patients move in a positive direction.

\section{Clinical implications}

Despite the amount of research in the field, ED are difficult to treat and results are often disheartening. By paying attention to patient tendencies to self-blame early in treatment and contributing to the development of a healthier self-image the development of the condition could progress in a positive direction.

\section{Abbreviations}

AN: Anorexia Nervosa; BMI: Body Mass Index; BED: Binge Eating Disorder; BN: Bulimia Nervosa; CFT: Compassion-focused Therapy; DSM: Diagnostic and Statistical Manual of Mental Disorders; ED: Eating Disorder; EDI-2: Eating Disorder Inventory, 2nd revision; OSFED: Other Specified Eating and Feeding Disorder; RAB: Rating of Anorexia and Bulimia; SASB: Structural Analysis of Social Behavior; SCL-90: Symptom Check List-90

\section{Acknowledgements}

This study was supported financially by Kalmar Regional Council, Sweden. The authors wish to thank Elisabet Lannfelt and Maja Molin for help with data collection, and Louise Högdahl for assisting in previous versions of the manuscript.

\section{Authors' contributions}

$A B$ and $D C$ conceived the study. CB collected the data. SP and LB performed statistical analyses. SP and $A B$ drafted the first versions of the manuscript which was further processed by the other authors. All authors approved the final manuscript.

\section{Funding}

Open Access funding provided by Linnaeus University.

\section{Availability of data and materials}

The datasets generated during and/or analysed during the current study are not publicly available due to patient confidentiality.

\section{Declarations}

\section{Ethics approval and consent to participate}

The study was conducted according to the principals of the Helsinki declaration. Prior to interviews participants were provided written and oral information about the study. It was pointed out that participation was voluntary, and that participation or refusal would not affect treatment. Participants were informed that presentation of the data would be handled with confidentiality so that no data could be traced to any single informant. The study was approved by the Regional Ethical Review Board at Karolinska Institute, Stockholm, Sweden (KI Dnr 02-124).

\section{Consent for publication}

Participants in the study were informed and signed a consent document. The document was approved by the Regional Ethical Review Board at Karolinska Institute, Stockholm, Sweden.

\section{Competing interests}

The authors declare they have no competing interests.

\section{Author details}

${ }^{1}$ Department of Rehabilitation, Kalmar Regional Council, Hus 13, plan 7, 391 85, Länssjukhuset, Kalmar, Sweden. ${ }^{2}$ Department for Medicine and Optometry, Linnaeus University, Kalmar, Sweden. ${ }^{3}$ Department of Medical Epidemiology and Biostatistics, Karolinska Institutet, Stockholm, Sweden.

${ }^{4}$ Department of Clinical Physiology, Region Kalmar County, Kalmar, Sweden. ${ }^{5}$ Department of Medical and Health Sciences, Linköping University, Linköping, Sweden. ${ }^{6}$ Centre for Psychiatry Research, Stockholm Health Care Services, Karolinska Institutet, Stockholm, Sweden. 'Department of Clinical Neuroscience, Karolinska Institutet, Stockholm, Sweden. ${ }^{8}$ Institute for Eating Disorders, Villa Sult, Oslo, Norway. ${ }^{9}$ Department of Neurobiology, Care Sciences and Society (NVS), Karolinska Institutet, Stockholm, Sweden.

Received: 31 March 2021 Accepted: 21 June 2021

Published online: 07 July 2021

\section{References}

1. Vall E, Wade TD. Predictors of treatment outcome in individuals with eating disorders: a systematic review and meta-analysis. Int J Eat Disord. 2015;48(7): 946-71. https://doi.org/10.1002/eat.22411.

2. Strober M, Freeman R, Morrell W. The long-term course of severe anorexia nervosa in adolescents: survival analysis of recovery, relapse, and outcome predictors over 10-15 years in a prospective study. Int J Eat Disord. 1997; 
22(4):339-60. https://doi.org/10.1002/(SICI)1098-108X(199712)22:4<339::AIDEAT1>3.0.CO;2-N.

3. Forney KJ, Crosby RD, Brown TA, Klein KM, Keel PK. A naturalistic, long-term follow-up of purging disorder. Psychol Med. 2020;51 (6):1-8. https://doi.org/1 $0.1017 / 50033291719003982$.

4. Garner DM. Eating disorder Inventory-2. Professional manual. Odessa, Florida: Psychological Assessment Resources, Inc; 1991.

5. Quadflieg N, Fichter MM. Long-term outcome of inpatients with bulimia nervosa - results from the Christina Barz study. Int J Eat Disord. 2019;52(7): 834-45. https://doi.org/10.1002/eat.23084.

6. Fichter MM, Quadflieg N, Crosby RD, Koch S. Long-term outcome of anorexia nervosa: results from a large clinical longitudinal study. Int J Eat Disord. 2017;50(9):1018-30. https://doi.org/10.1002/eat.22736.

7. Carrot B, Radon L, Hubert T, Vibert S, Duclos J, Curt F, et al. Are lifetime affective disorders predictive of long-term outcome in severe adolescent anorexia nervosa? Eur Child Adolesc Psychiatry. 2017;26(8):969-78. https:// doi.org/10.1007/s00787-017-0963-5.

8. Franko DL, Tabri N, Keshaviah A, Murray HB, Herzog DB, Thomas JJ, et al. Predictors of long-term recovery in anorexia nervosa and bulimia nervosa: data from a 22-year longitudinal study. J Psychiatr Res. 2018;96:183-8 https://doi.org/10.1016/j.jpsychires.2017.10.008

9. Birgegård A, Björck C, Norring C, Sohlberg S, Clinton B. Anorexic self-control and bulimic self-hate: differential outcome prediction from initial self-image. Int J Eat Disord. 2009;42(6):522-30. https://doi.org/10.1002/eat.20642.

10. Björck C, Clinton D, Sohlberg S, Norring C. Negative self-image and prognosis in eating disorders: results at 3 years follow-up. Eat Behav. 2007; 8(3):398-406. https://doi.org/10.1016/j.eatbeh.2006.12.002.

11. Forsén Mantilla E, Norring C, Birgegård A. Self-image and 12-month outcome in females with eating disorders: extending previous findings. J Eat Disord 2019; 7 (15). doi: https://doi.org/10.1186/s40337-019-0247-1.

12. Benjamin LS. A clinician-friendly version of the interpersonal circumplex: structural analysis of social behavior (SASB). J Pers. 1996;66(2):248-66. https://doi.org/10.1207/s15327752jpa6602_5.

13. Benjamin LS. SASB Intrex user's manual. Salt Lake City: University of Utah; 2000.

14. Andersen $M$, Birgegård $A$. Diagnosis-specific self-image predicts longitudinal suicidal ideation in adult eating disorders. Int J Eat Disord. 2017;50(8):970-8. https://doi.org/10.1002/eat.22730.

15. Björck C, Björk T, Clinton D, Sohlberg S, Norring C. Self-image and treatment drop-out in eating disorders. Psychol Psychother. 2008;81(1):95-104. https:// doi.org/10.1348/147608307X224547.

16. Steinhausen HC. Outcome of eating disorders. Child Adolesc Psychiatr Clin N Am. 2008;18(1):225-42. https://doi.org/10.1016/j.chc.2008.07.013.

17. Bardone-Cone AM, Schaefer LM, Maldonado CR, Fitzimmons EE, Harney MB, Lawson MA, et al. Aspects of self-concept and eating disorder recovery: what does the sense of self look like when an individual recovers from an eating disorder? J Soc Clin Psychol. 2010;29(7):821-46. https://doi.org/10.1 521/jscp2010297821.

18. Bardone-Cone AM, Harney MB, Maldonado CR, Lawson MA, Robinson DP, Smith $R$, et al. Defining recovery from an eating disorder: conceptualization, validation, and examination of psychosocial functioning and psychiatric comorbidity. Behav Res Ther. 2010;48(3):194-202. https://doi.org/10.1016/j. brat.2009.11.001.

19. Bardone-Cone AM, Hunt RA, Watson HJ. An overview of conceptualizations of eating disorder recovery, recent findings, and future directions. Curr Psychiatry Rep. 2018:20(9). https://doi.org/10.1007/s11920-018-0932-9.

20. Björk T, Clinton D, Norring C. The impact of different outcome measures on estimates of remission in a 3-year follow-up of eating disorders. Eur Eat Disord Rev. 2011;19(1):2-11. https://doi.org/10.1002/erv.1031 PMID: 20597067.

21. American Psychiatric Association, APA. Diagnostic and statistical manual of mental disorders. 4th ed. Washington DC: APA; 1994

22. Hansson LM, Björck C, Birgegård A, Clinton D. How do eating disorder patients eat after treatment? Dietary habits and eating behaviour three years after entering treatment. Eat Weight Disord. 2011;16:e1-8. E-ISSN: 1590-1262. https://doi.org/10.1007/BF03327514.

23. Nevonen L, Broberg AG, Clinton D, Norring C. A measure for the assessing of eating disorders: reliability and validity studies of the rating of anorexia and bulimia interview - revised version (RAB-R). Scand J Psyc. 2003;44(4): 303-10. https://doi.org/10.1111/1467-9450.00349.

24. Nevonen L, Clinton D, Norring C. Validating the EDI-2 in three Swedish female samples: eating disorders patients, psychiatric outpatients and normal controls. Nord J Psychiatry. 2006;60(1):44-50. https://doi.org/10.1080/ 08039480500504537

25. Armelius K. Reliabilitet och validitet för den svenska versionen av SASB självbildstestet. [Reliability and validity for the Swedish version of SASBintroject test]. Unpublished manuscript. Department of psychology, University of Umeå, Sweden; 2001.

26. Monell E. Emotion dysregulation, self-image, and eating disorders. Thesis. Stockholm: Karolinska Institute; 2021. https://openarchive.ki.se/xmlui/ha ndle/10616/47616

27. Björck C, Clinton D, Sohlberg S, Hällström T, Norring C. Interpersonal profiles in eating disorders: ratings of SASB self-image. Psychol Psychother. 2003; 76(4):337-49. https://doi.org/10.1348/147608303770584719.

28. Forsén Mantilla E, Bergsten $K$, Birgegård A. Self-image and eating disorder symptoms in normal and clinical adolescents. Eat Behav. 2014;15(1):125-31. https://doi.org/10.1016/j.eatbeh.2013.11.008.

29. Forsén Mantilla E, Birgegård A. The enemy within: the association between self-image and eating disorder symptoms in healthy, non-help seeking and clinical young women. J Eat Disord. 2015;3(30). https://doi.org/10.1186/s4 0337-015-0067-x.

30. Derogatis LR, Lipman RS, Covi L. SCL-90: an outpatient psychiatric rating scale - preliminary report. Psychopharmacol Bull. 1973:9(1):13-28.

31. Fridell $M$, Cesarec $Z$, Johansson M, Malling TS. SCL-90: svensk normering, standardisering och validering av symtomskalan (in Swedish) The SCL-90: Swedish norms, standardization, and validation of the symptom checklist]. Stockholm: Statens institutionsstyrelse (SiS); 2002.

32. Ametller L, Castro J, Serrano E, Marti'nez E, Toro J. Readiness to recover in adolescent anorexia nervosa: prediction of hospital admission. J Child Psychol Psychiatr. 2005;46(4):394-400. https://doi.org/10.1111/j.1469-7610.2 004.00360.x.

33. Carrard I, Fernandez-Aranda F, Lam T, Nevonen L, Liwowsky I, Volkart A, et al. Evaluation of a guided internet self-treatment programme for bulimia nervosa in several European countries. Eur Eat Disord Rev. 2010;19(2):138-49. https:// doi.org/10.1002/erv.1043.

34. Danielsen $M, R \varnothing \varnothing$. Changes in body image during inpatient treatment for eating disorders predict outcome. Eat Disord. 2012;20(4):261-75. https://doi. org/10.1080/10640266.2012.689205.

35. Ricca V, Castellini G, Lo Sauro C, Mannucci E, Ravaldi C, Rotella F, et al. Cognitive-behavioral therapy for threshold and subthreshold anorexia nervosa: A three-year follow-up study. Psychother Psychosom. 2010;79(4): 238-48. https://doi.org/10.1159/000315129.

36. Trottier K, McFarlane T, Olmsted MP. A test of the weight-based selfevaluation Schema in eating disorders: understanding the link between selfesteem, weight-based self-evaluation, and body dissatisfaction. Cogn Ther Res. 2013;37(1):122-6. https://doi.org/10.1007/s10608-012-9446-7.

37. Prefit $A B$, Cândea DM, Szentagatai-Tătar A. Emotion regulation across eating pathology: A meta-analysis. Appetite. 2019;143:104438. https://doi.org/10.1 016/j.appet.2019.104438.

38. Fairburn CG, Cooper Z, Shafran R. Cognitive behavior therapy for eating disorders: a "transdiagnostic" theory and treatment. Behav Res Ther. 2003; 41(5):509-28. https://doi.org/10.1016/50005-7967(02)00088-8.

39. Petersson S, Johnsson P, Perseius Kl. A Sisyphean task: experiences of perfectionism in patients with eating disorders. J Eat Disord. 2017;5(3):1-11. https://doi.org/10.1186/s40337-017-0136-4.

40. Puttevils L, Vanderhasselt MA, Vervaet M. Investigating transdiagnostic factors in eating disorders - does self-esteem moderate the relationship between perfectionism and eating disorders symptoms? Eur Eat Disord Rev. 2019;27(4):381-90. https://doi.org/10.1002/erv.2666.

41. Kelly AC, Tasca GA. Within-persons predictors of change during eating disorders treatment: an examination of self-compassion, self-criticism, shame, and eating disorder symptoms. Int J Eat Disord. 2016;49(7):716-22. https://doi.org/10.1002/eat.22527.

42. Gezelius C, Wahlund B, Carlsson L, Wiberg B. Adolescent patients with eating disorders and their parents: a study of self-image and outcome at an intensive outpatient program. Eat Weight Disord. 2016;21(4):607-16. https:// doi.org/10.1007/s40519-016-0286-4.

43. Goss K, Allan S. The development and application of compassion-focused therapy for eating disorders (CFT-E). Br J Clin Psychol. 2014;53(1):62-77. https://doi.org/10.1111/bjc.12039.

44. Werner AM, Tibubos AN, Rohrmann S, Reiss N. The clinical trait self-criticism and its relation to psychopathology: A systematic review - update. J Affect Disord. 2019;246:530-47. https://doi.org/10.1016/j.jad.2018.12.06. 
45. Kelly AC, Wisniewski L, Martin-Wagar C, Hoffman E. Group-based compassion-focused therapy as an adjunct to outpatient treatment for eating disorders: A pilot randomised controlled trial. Clin Psychol Psychother. 2016;24(2):475-87. https://doi.org/10.1002/cpp.2018.

46. American Psychiatric Association, APA. Diagnostic and statistical manual of mental disorders (5th ed.). Arlington: APA; 2013.

\section{Publisher's Note}

Springer Nature remains neutral with regard to jurisdictional claims in published maps and institutional affiliations.

Ready to submit your research? Choose BMC and benefit from:

- fast, convenient online submission

- thorough peer review by experienced researchers in your field

- rapid publication on acceptance

- support for research data, including large and complex data types

- gold Open Access which fosters wider collaboration and increased citations

- maximum visibility for your research: over $100 \mathrm{M}$ website views per year

At BMC, research is always in progress.

Learn more biomedcentral.com/submissions 